\title{
PHYTOCHEMICAL SCREENING, ANTIOXIDANT ACTIVITY AND EXTRACTION OF ACTIVE COMPOUND (ANONAINE) FROM FRUIT PEEL EXTRACT OF ANNONA RETICULATA L.
}

\author{
SUMATHI ETHIRAJ*, VANDANA SRIDAR \\ Department of Biotechnology, University of Madras, Guindy Campus, Chennai, Tamil Nadu, India. Email: sumathiethiraj@yahoo.com
}

Received: 08 June 2018, Revised and Accepted: 24 July 2018

ABSTRACT

Objective: The main objective of this study was to analyze the phytochemical constituents, total phenol, total flavonoid, alkaloid content, in vitro antioxidant activity and high-performance liquid chromatography (HPLC) analysis of anonaine compound from the fruit peel extract of Annona reticulata $\mathrm{L}$

Methods: Preliminary phytochemical analysis for alkaloids, cardiac glycosides, flavonoids, glycosides, phenols, saponins, steroids, tannins, and terpenoids was studied. Quantitative phytochemical analysis for total phenolics, total flavonoids and alkaloids was determined according to standard protocols. In vitro antioxidant potential was evaluated by assessing 1,1-diphenyl-2-picrylhydrazyl (DPPH) radical scavenging activity by following standard procedure. HPLC analysis was carried out to identify a major metabolite, namely, anonaine compound from fruit peel extract of $A$. reticulata $\mathrm{L}$.

Results: Phytochemical screening of various extracts such as aqueous, ethanol, chloroform, acetone, and petroleum ether of fruit peel extracts revealed the presence of tannins, saponins, phenols, flavonoids, cardiac glycosides, coumarins, terpenoids, alkaloids, and steroids. Total phenol, flavonoid and alkaloid contents were quantitatively estimated which recorded maximum in Ooty accession $(17.75 \pm 0.13 \mathrm{mg}$ gallic acid equivalents/g, $13.97 \pm 0.21 \mathrm{mg}$ quercetin equivalents/g, and alkaloid content of $6.92 \pm 0.14 \mathrm{mg} / \mathrm{g}$ ), respectively. Among three accessions with five different solvents used, maximum antioxidant activity was found in aqueous peel extract $(90.76 \pm 1.3 \%)$ from Ooty accession followed by others. The results of HPLC analysis in the fruit peel extract of $A$. reticulata proved the presence of the active principle, namely anonaine compound.

Conclusion: Therefore, this study suggests the possibility of using fruit peel extracts of A. reticulata as a potent source of natural antioxidant and thus could prevent many free radical mediated diseases. The validated HPLC method can be used for routine quality control analysis.

Keywords: Annona reticulata, Phytochemical screening, Phenols, flavonoids, Antioxidant activity, High-performance liquid chromatography.

(C) 2018 The Authors. Published by Innovare Academic Sciences Pvt Ltd. This is an open access article under the CC BY license (http://creativecommons. org/licenses/by/4. 0/) DOI: http://dx.doi.org/10.22159/ajpcr.2018.v11i11.27838

\section{INTRODUCTION}

Medicinal plants are still major part of traditional medicinal system in the developing countries and many infectious diseases are known to be treated with herbal remedies throughout the history of mankind. Even today, plant materials continue to play a major role in primary health care as therapeutic remedies in many developing countries [1]. Recent studies have reported that natural antioxidants obtained from medicinal plants protect from toxic and harmful effects of free radicals and have a wide range of pharmacological effects, including antimicrobial, antimutagenic, anti-allergic, antioxidant free radical scavenging activity and anti-carcinogenic effects [2]. There is an increasing trend in correlating phytochemical constituents of plants with its pharmacological activities [3].

Phytochemicals such as alkaloids, tannins and flavonoids are examples of secondary metabolites produced by plants, from which the plants are thought to get their healing properties [4]. Phenolic compounds have been associated with antioxidant activity due to their free radical scavenging activities [5]. Potentially active components from fruits, herbs, roots and leaves have been studied extensively to avoid oxidative cellular events [6]. Antioxidants are a group of substances that are useful for fighting cancer and other processes that potentially lead to diseases such as atherosclerosis, Alzheimer, Parkinson, diabetes and heart disease [7]. Oxidants damage macromolecules such as proteins, lipids, enzymes, DNA and to combat these radicals, living organisms produce enzymes or rely on non-enzymatic molecules such as cysteine, ascorbic acid, flavonoids, and Vitamin K for production [8]. Natural antioxidants present in plant origin protect against these radicals and are therefore important tools in obtaining and preserving good health [9].
The flavonoids have aroused considerable interest recently because of their potential beneficial effects on human health [10]. Quercetin is a type of flavonol and the best property of quercetin is that it acts as an antioxidant [11]. The presence of antioxidants such as phenolics, flavonoids, tannins, and proanthocyanidins in plants may provide protection against a number of diseases; for example, ingestion of natural antioxidants has been inversely associated with morbidity and mortality from degenerative disorders [12]. Medicinal plants are, therefore, being investigated for their antioxidant properties, and the demand for natural antioxidants and food preservatives is increasing [13]. High-performance liquid chromatography (HPLC) is highly sensitive method for detection, identification and quantification of any chemical in particular samples using ultraviolet and visible (UVvisible) absorbance [14]. On comparing with the retention time of the standards, phenolic compounds can be identified [15].

The plant Annona reticulata L. one of the traditionally important plants used for the treatment of various ailments belongs to the family Annonaceae. It is commonly known as Ramphal, Bullock's heart, and Custard apple and it is native to India [16]. It grows naturally in tropical and subtropical region. In the rural area, plant parts such as leaves, bark, seed, and root are used as folk medicine to combat against different disease conditions. Various extracts of different plant parts have shown anti-hyperglycemic, cytotoxic and recombinant caspase inhibitory activity, antinociceptive, analgesic and central nervous system depressant, analgesic and anti-inflammatory, tumor inhibitor and anti-proliferative [17]. The present research work has been designed to determine the phytochemical screening, total phenols, flavonoid content, antioxidative properties and HPLC analysis of anonaine compound from the fruit peel extract of Annona reticulata $\mathrm{L}$. 


\section{METHODS}

\section{Collection of $A$. reticulata}

The $A$. reticulata fruits (Fig. 1) used in the present investigation were collected from three different places in Tamil Nadu namely Ooty, Kodaikanal and Kolli Hills. The collected plant material was identified and authenticated by Dr. T. Sekar, Associate professor, PG and Research Department of Botany, Pachaiyappa's College, Chennai, Tamil Nadu, India. The fruit peels were washed with distilled water and subjected to shade dry at room temperature in the Department of Biotechnology, University of Madras, Guindy Campus, Chennai-600 025.

\section{Preparation of the fruit peel extract}

The polar (aqueous, ethanol, and acetone) and non-polar (petroleum ether and chloroform) fruit peel extracts were analyzed for phytochemical constituents (phenol, alkaloids, flavonoids, etc.) using standard qualitative methods [18]. $1 \mathrm{~g}$ of dried fruit peel material was ground in a mortar and pestle with $15 \mathrm{~mL}$ of respective solvent, extracted for $5 \mathrm{~min}$ at $55^{\circ} \mathrm{C}$ and centrifuged at $9000 \mathrm{rpm}$ for $5 \mathrm{~min}$. This procedure was repeated 2 times and the supernatants were collected and concentrated. The concentrated extracts were stored in an airtight container in the refrigerator below $10^{\circ} \mathrm{C}$.

Qualitative phytochemical analysis from fruit peel extracts of A. reticulata

The prepared solvent extracts were subjected to preliminary phytochemical analysis for the presence of active secondary metabolites. Each extract was tested separately with specific chemical reagents according to standard procedures [19]. Visible color change or precipitate formation was taken into consideration for the presence $(+)$ or absence (-) of particular active constituents.

\section{Qualitative analysis of the Antioxidant activity of fruit peel extracts} of $A$. reticulata

The antioxidant activity of the fruit peel extracts of $A$. reticulata was screened according to the method as described by George et al. [20]. $50 \mu \mathrm{L}$ of different solvents such as polar (aqueous, ethanol, and acetone) and non-polar (petroleum ether and chloroform) fruit peel extracts of $A$. reticulata were taken in the microtiter plate. $100 \mu \mathrm{L}$ of $0.1 \%$ methanolic DPPH was added with the samples and incubated for $30 \mathrm{~min}$ in the dark condition. Then, the samples were observed for discoloration from purple to yellow and pale pink which were considered as strong and weak positive, respectively. The antioxidant positive samples were subjected for further quantitative analysis.

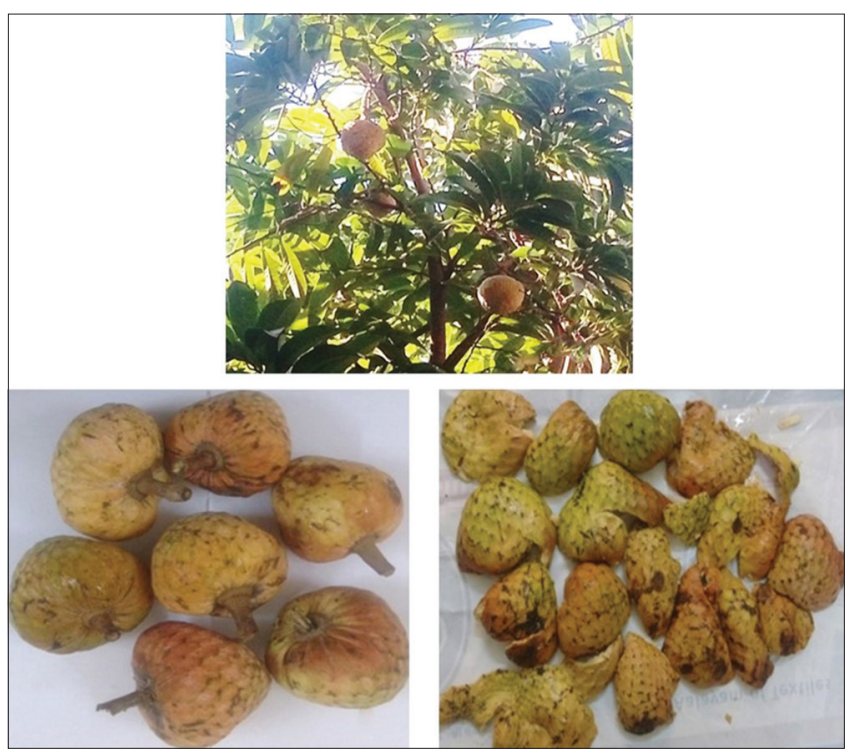

Fig. 1: Mother plant of Annona reticulata (Ooty accession). (a) A. reticulata mother plant, (b) $A$. reticulata fruit, (c) $A$. reticulata fruit peel (shade drying)
Quantitative analysis of the antioxidant activity of fruit peel extracts of $A$. reticulata

The antioxidant potential of the each respective solvent extracts was quantified on the basis of their scavenging activity of the stable 1,1-diphenyl-2-picrylhydrazyl (DPPH) free radical. Briefly, $100 \mu \mathrm{L}$ of various solvent fruit peel extracts was mixed with $2.7 \mathrm{~mL}$ of methanol and then, $200 \mu \mathrm{L}$ of $0.1 \%$ methanolic DPPH was added. The mixture was vigorously shaken and allowed to stand at room temperature for $30 \mathrm{~min}$ in the dark. The absorbance of the mixture was measured at $517 \mathrm{~nm}$ using a double-beam UV-visible (Chemito, India) spectrophotometer [21]. The free radical scavenging activity of the sample was compared with the known synthetic standard of $0.16 \%$ butylated hydroxytoluene (BHT). Free radical scavenging activity was calculated by the following formula:

$\%$ DPPH radical scavenging $=[($ Absorbance of control - Absorbance of test sample)/(Absorbance of control) $] \times 100$

\section{Quantification of total phenolic contents in fruit peel extract of} A. reticulata

The amount of total phenolic content in the aqueous fruit peel extracts of $A$. reticulata was determined using Folin-Ciocalteu reagent [22]. To $0.5 \mathrm{ml}$ of peel extract of A. reticulata, distilled water and Folin's Ciocalteu reagent was added. The contents were mixed and incubated for 5 minutes. After incubation, $10 \mathrm{ml}$ of $(10 \% \mathrm{~W} / \mathrm{V})$ sodium carbonate was added and the contents were mixed and allowed to stand for $30 \mathrm{~min}$. Absorbance at $725 \mathrm{~nm}$ was measured in a UV-visible spectrophotometer. The amount of total phenolics was calculated as gallic acid equivalent (GAE) in mg per $\mathrm{g}$ of dry weight.

Determination of total flavonoid content in fruit peel extract of $A$. reticulata

The amount of total flavonoid content in the aqueous fruit peel extracts was determined by aluminum chloride colorimetric method [23]. $0.5 \mathrm{~mL}$ of fruit peel extract of $A$. reticulata at a concentration of $1 \mathrm{mg} / \mathrm{mL}$ was taken and the volume was made up to $3 \mathrm{~mL}$. Then, $0.1 \mathrm{~mL}$ of aluminum chloride $(10 \%), 0.1 \mathrm{~mL}$ of potassium acetate and $2.8 \mathrm{~mL}$ of distilled water were added sequentially. The test solution was vigorously shaken. Absorbance was recorded at $415 \mathrm{~nm}$ after $30 \mathrm{~min}$ of incubation. A standard calibration plot was generated at $415 \mathrm{~nm}$ using known concentrations of quercetin. The concentrations of flavonoid in the test samples were calculated from the calibration plot and expressed as mg quercetin equivalent (QE)/g of sample.

\section{Quantification of alkaloids in fruit peel extract of $A$. reticulata}

Quantitative estimation of alkaloids was carried out following the method of Edeoga et al. and Okwu and Josiah [24,25]. $2.5 \mathrm{~g}$ of the fruit peel powder was extracted using $100 \mathrm{~mL}$ of $20 \%$ acetic acid in ethanol. The solution was allowed to stand at room temperature for almost $4 \mathrm{~h}$. The filtrate was concentrated to $25 \mathrm{~mL}$. Concentrated ammonium hydroxide was added stepwise until precipitation appeared. The whole solution was kept as such so that precipitate settled completely. Collected precipitate was washed with dilute ammonium hydroxide and finally filtered. Filtrate was discarded, pellet obtained was dried, and total alkaloid content recorded.

\section{HPLC analysis of anonaine compound}

The fine powder of the fruit peel biomass was extracted with $75 \%$ of ethanol and then, the extract was evaporated. The residue of extract was mixed with n-butanol and water (2:1), and both the upper layer of n-butanol and lower layer of water were separated and evaporated under vacuum. The residues were washed with petroleum ether to remove fatty components and then extracted with methanol. The concentrated extract in methanol was separated and analyzed using HPLC as per standard method [26]. The extracts were filtered through Sartorius regenerated cellulose membrane syringe filter $(0.2 \mu)$ and $20 \mu \mathrm{L}$ of the filtrate was injected into the HPLC. Chromatography was performed using Shimadzu HPLC (Model SPD-10A UV-visible Detector) and Supelcosil LC-18 column $(25 \mathrm{~cm} \times 4.6 \mathrm{~mm}, 5 \mathrm{~m})$ with mobile phase 
consisting of acetonitrile, water and acetic acid (50:50:0.1). Flow rate was maintained at $1.0 \mathrm{~mL} / \mathrm{min}$ with a back pressure of $250 \mathrm{psi}$, and the compounds were read at $270 \mathrm{~nm}$ using a UV detector. The total run time was $20 \mathrm{~min}$, but preferably it was extended up to $40 \mathrm{~min}$ [27]. The results were compared with standard.

\section{RESULTS AND DISCUSSION}

The present study revealed that the polar (aqueous, ethanol, and acetone) and non-polar (petroleum ether and chloroform) solvent extracts were obtained from the fruit peel of $A$. reticulata collected from different places namely Ooty, Kodaikanal, and Kolli Hills. The results of phytochemicals analysis are presented in Tables 1-3. The phytochemical screening of five different solvent extracts recorded maximum presence of phytochemical detection of chemical constituents and showed that the aqueous extract of fruit peel of $A$. reticulata (Ooty accession) was rich in phenols, tannins, saponins, flavonoids, alkaloids, terpenoids, steroids, and cardiac glycosides followed by fruit collected from Kodaikanal and Kolli Hills. The results also recorded maximum phytochemical constituents in aqueous extract of all three fruit peel

Table 1: Phytochemical screening from fruit peel extracts of $A$. reticulata (Ooty accession)

\begin{tabular}{|c|c|c|c|c|c|}
\hline \multirow[t]{2}{*}{ Phytochemicals tested } & \multicolumn{5}{|c|}{ Fruit peel extracts of $A$. reticulata } \\
\hline & Aqueous & Ethanol & Chloroform & Petroleum ether & Acetone \\
\hline Tannins & ++ & + & - & - & + \\
\hline Quinones & ++ & ++ & + & + & ++ \\
\hline Terpenoids & ++ & + & - & - & - \\
\hline Steroids & + & + & + & - & + \\
\hline Flavonoids & ++ & ++ & - & - & + \\
\hline Phenol & ++ & ++ & + & + & + \\
\hline Alkaloids & + & + & - & - & - \\
\hline Glycosides & + & - & - & - & - \\
\hline Cardiac glycosides & ++ & + & + & + & + \\
\hline Coumarins & ++ & + & - & - & + \\
\hline Anthocyanin & - & - & - & - & - \\
\hline Betacyanin & + & + & - & - & + \\
\hline
\end{tabular}

++: Strong positive, +: Positive, -: Negative. A. reticulata: Annona reticulata

Table 2: Phytochemical screening from fruit peel extracts of $A$. reticulata (Kodaikanal accession)

\begin{tabular}{|c|c|c|c|c|c|}
\hline \multirow[t]{2}{*}{ Phytochemicals tested } & \multicolumn{5}{|c|}{ Fruit peel extracts of $A$. reticulata } \\
\hline & Aqueous & Ethanol & Chloroform & Petroleum ether & Acetone \\
\hline Tannins & ++ & + & - & - & + \\
\hline Saponins & + & + & + & + & - \\
\hline Quinones & + & + & + & + & + \\
\hline Terpenoids & ++ & + & - & - & - \\
\hline Steroids & + & + & + & - & + \\
\hline Flavonoids & ++ & ++ & - & - & - \\
\hline Phenol & ++ & ++ & + & + & + \\
\hline Alkaloids & + & + & - & - & - \\
\hline Glycosides & - & - & - & - & - \\
\hline Cardiac glycosides & + & + & + & + & + \\
\hline Coumarins & + & + & - & - & + \\
\hline Anthocyanin & - & - & - & - & - \\
\hline Betacyanin & + & + & - & - & + \\
\hline
\end{tabular}

++: Strong positive, +: Positive, -: Negative. A. reticulata: Annona reticulata

Table 3: Phytochemical screening from fruit peel extracts of $A$. reticulata (Kolli Hills accession)

\begin{tabular}{|c|c|c|c|c|c|}
\hline \multirow[t]{2}{*}{ Phytochemicals tested } & \multicolumn{5}{|c|}{ Fruit peel extracts of $A$. reticulata } \\
\hline & Aqueous & Ethanol & Chloroform & Petroleum ether & Acetone \\
\hline Tannins & + & + & - & - & + \\
\hline Saponins & + & + & + & + & - \\
\hline Quinones & + & + & + & + & + \\
\hline Terpenoids & ++ & + & - & - & - \\
\hline Steroids & ++ & + & + & - & + \\
\hline Flavonoids & ++ & + & - & - & + \\
\hline Phenol & ++ & + & + & + & + \\
\hline Alkaloids & + & + & - & - & - \\
\hline Glycosides & - & - & - & - & - \\
\hline Cardiac glycosides & + & + & + & + & - \\
\hline Coumarins & + & + & - & - & + \\
\hline Anthocyanin & - & - & - & - & - \\
\hline Betacyanin & + & + & - & - & + \\
\hline
\end{tabular}

++: Strong positive, +: Positive, -: Negative. A. reticulata: Annona reticulata 
extracts than other solvents such as ethanol, acetone, chloroform and petroleum ether extract. Thus, the preliminary screening tests would be useful in the detection of the bioactive principles, leading to drug discovery and development. These secondary metabolites are reported to have many biological and therapeutic properties [28]. Further, these tests facilitate their quantitative estimation and qualitative separation of pharmacologically active chemical compounds.

A. reticulata fruit peel extracts were subjected for the evaluation of antioxidant activity. Table 4 shows the qualitative antioxidant analysis in the fruit peel extracts of $A$. reticulata collected from three different places of Tamil Nadu. DPPH radical scavenging activity was observed in all the extracts and the results revealed a strong positive response for aqueous fruit peel extract (Ooty), followed by others.

This is a widely used method to evaluate antioxidant activities in a relatively short time compared with other methods. Antioxidants react with DPPH which is a stable free radical and convert it to DPPH hydrazine. The degree of decolorization indicates the scavenging potentials of the antioxidant compounds. The percentage of DPPH radical scavenging activity of aqueous fruit peel extracts of $A$. reticulata from various accessions is shown in Fig. 2-4.

The results revealed that, among three accessions and five different solvent extracts of $A$. reticulata, the aqueous peel extract collected from Ooty accession had maximum DPPH radical scavenging activity $(90.76 \pm 1.3 \%)$ followed by Kodaikanal $(83.47 \pm 2.25 \%)$ and Kolli Hills accession $(81.26 \pm 1.2 \%)$, when compared with that of synthetic antioxidant BHT as a positive control (98.36 $\pm 0.90 \%)$.

In all accessions, aqueous fruit peel extracts recorded a higher percentage of free radical scavenging activity followed by ethanol, acetone, chloroform, and petroleum ether. The decrease in absorbance of DPPH radical is caused by antioxidant through the reaction between antioxidant molecule and radical results in the scavenging of the radical by hydrogen donation [29]. Scavenging activity for free radicals of DPPH has been widely used to evaluate the antioxidant activity of natural products from plant and natural sources. Free radicals have a broad range of effects in biological systems. It has been proved that these mechanisms may be important in the pathogenesis of certain diseases and aging. Many synthetic antioxidant components have shown toxic and/or mutagenic effects which have shifted the attention toward the naturally occurring antioxidants $[30,31]$. Free radicals are involved in many disorders such as neurodegenerative diseases and

Table 4: Qualitative analysis of antioxidant activity of fruit peel extract of Annona reticulata

\begin{tabular}{|c|c|c|c|}
\hline Extractions & $\begin{array}{l}\text { A. reticulata } \\
\text { (Ooty) }\end{array}$ & $\begin{array}{l}\text { A. reticulata } \\
\text { (kodaikanal) }\end{array}$ & $\begin{array}{l}\text { A. reticulata } \\
\text { (kolli Hills) }\end{array}$ \\
\hline Control & - & - & - \\
\hline BHT - standard & ++ & ++ & ++ \\
\hline Petroleum ether & Semi positive & Semi positive & Semi positive \\
\hline Chloroform & Semi positive & Semi positive & Semi positive \\
\hline Acetone & + & + & + \\
\hline Ethanol & + & + & + \\
\hline Aqueous & ++ & ++ & ++ \\
\hline
\end{tabular}

A. reticulata: Annona reticulata

Table 5: Quantification of phytochemicals from fruit peel extract of $A$. reticulata (Ooty accession)

\begin{tabular}{llll}
\hline A. reticulata & $\begin{array}{l}\text { TPC } \\
\text { (mg GAE/g) }\end{array}$ & $\begin{array}{l}\text { Total flavonoid } \\
\text { content (mg QE/g) }\end{array}$ & $\begin{array}{l}\text { Total alkaloid } \\
\text { content (mg/g) }\end{array}$ \\
\hline $\begin{array}{l}\text { Fruit peel } \\
\text { extract }\end{array}$ & $17.75 \pm 0.13$ & $13.97 \pm 0.21$ & $6.92 \pm 0.14$ \\
\hline
\end{tabular}

Results represent mean \pm SD of three replicated experiments.

A. reticulata: Annona reticulata, TPC: Total phenolic content cancer. Antioxidants due to their scavenging activity are useful for the management of those diseases [32].

The plant phenolics constitute one of the major groups of compounds acting as primary antioxidants or free radical terminators, so it was reasonable to determine their total amount in the fruit peel extracts. In our study, total phenol content of A. reticulata (Ooty) fruit peel extracts was estimated using Folin-Ciocalteu colorimetric method

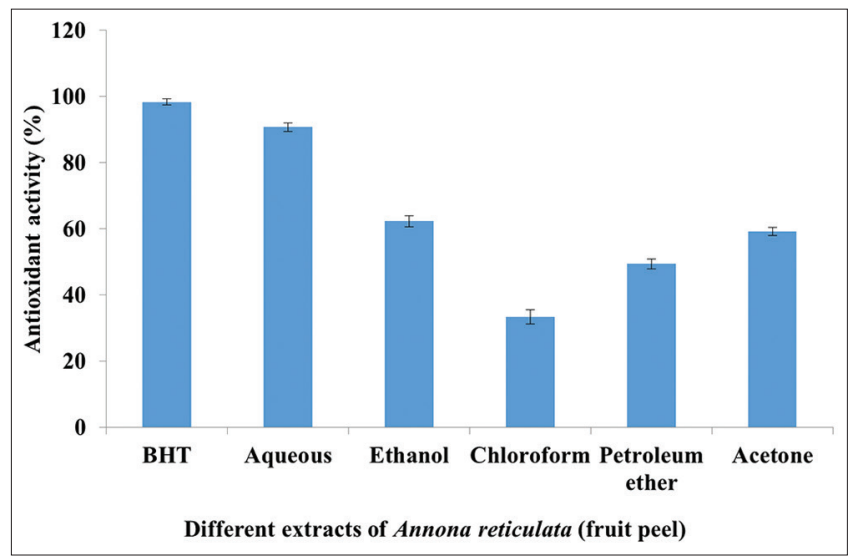

Fig. 2: Quantitative analysis of the antioxidant activity of Annona reticulata (Ooty). Results represent mean \pm standard deviation of three replicated experiments

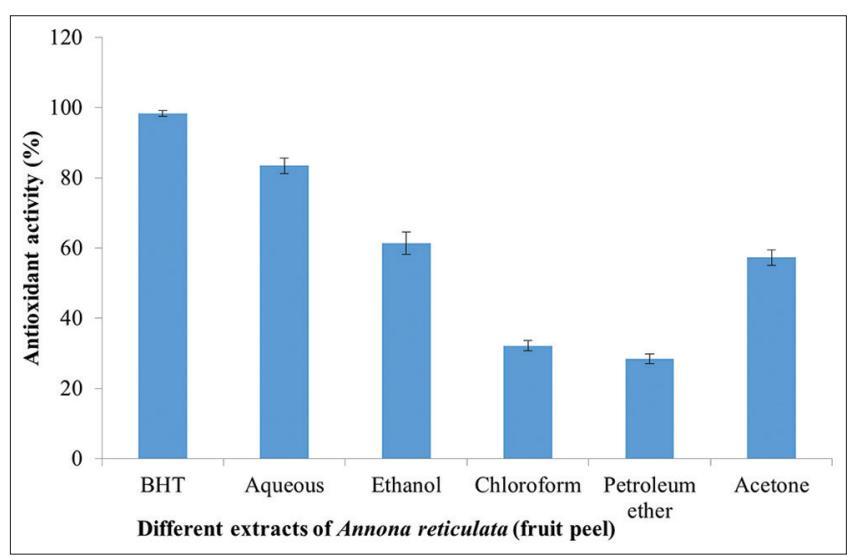

Fig. 3: Quantitative analysis of the antioxidant activity of Annona reticulata (Kodaikanal). Results represent mean \pm standard deviation of three replicated experiments

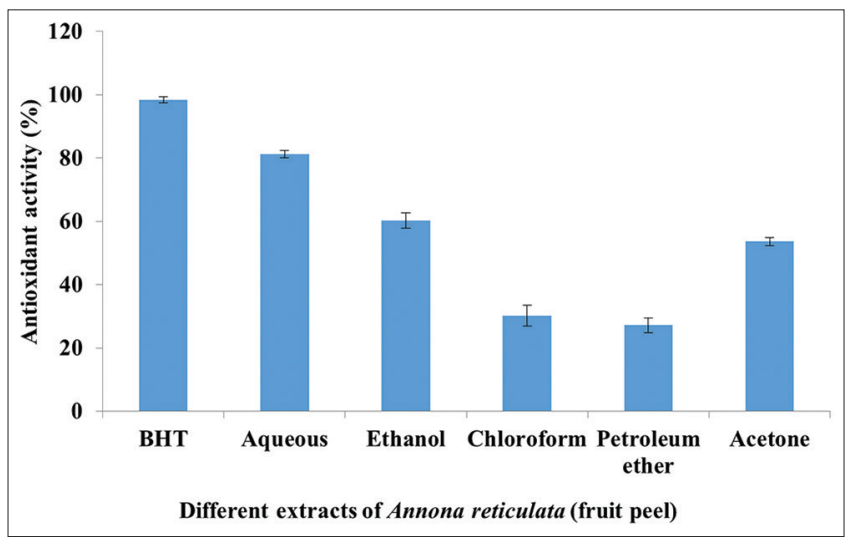

Fig. 4: Quantitative analysis of the antioxidant activity of Annona reticulata (Kolli Hills). Results represent mean \pm standard deviation of three replicated experiments 


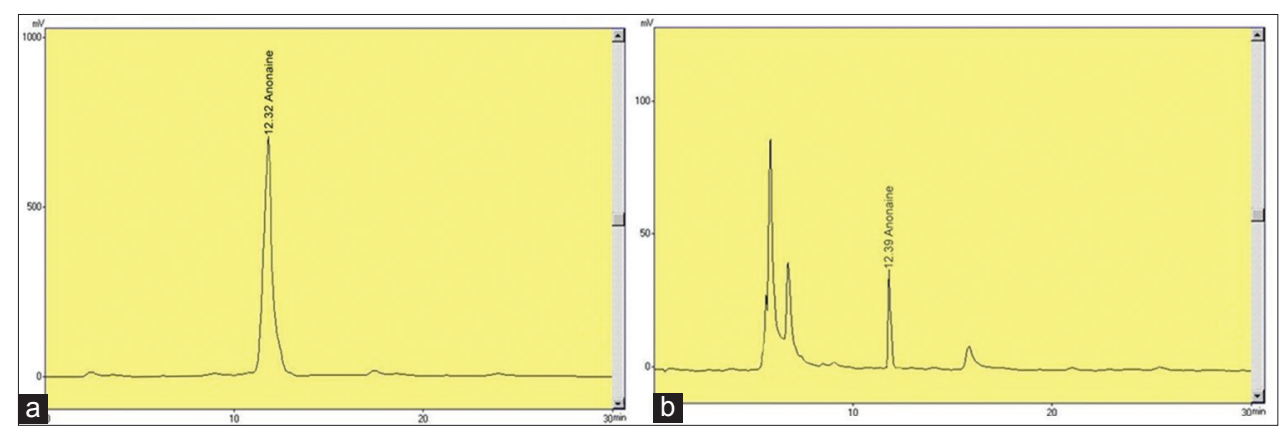

Fig. 5: High-performance liquid chromatography (HPLC) analysis of anonaine compound. (a) Anonaine standard (1 mg/1 mL), (b) HPLC of anonaine compound from the fruit peel extract of Annona reticulata (Ooty accession)

and represented in terms of GAE. The results of the present study showed that the phenol contents of the aqueous fruit peel extract in terms of GAE were $17.75 \pm 0.13 \mathrm{mg}$ GAE/g. Phenolic compounds are effective hydrogen donors, making them good antioxidants [33]. Flavonoids are regarded as one of the most widespread groups of natural constituents found in plants. Flavonoids are a class of secondary plant metabolites with significant antioxidant and chelating properties [34]. The results of the present study showed that the flavonoid contents of the aqueous fruit peel extract in terms of QE were found to be maximum $(13.97 \pm 0.21 \mathrm{mg} \mathrm{QE} / \mathrm{g})$. Alkaloids, widely existing in natural plants, are compounds containing basic nitrogen atoms. Most of alkaloids are pharmacologically active ingredients in many medicinal plants due to their significant physiological activity [35]. Results in Table 5 showed that the yield of alkaloids $(6.92 \pm 0.14 \mathrm{mg} / \mathrm{g})$ is obtained from aqueous fruit peel extracts of A. reticulata. This result is similar to Omulokoli et al. [36] and Monica et al. [37] where positive result obtained for phenols and alkaloids in high level and referred noted differences between plant parts in which alkaloids and flavonoids in peel and flower were higher than seeds and leaves. The findings were also supported by results [38] in which peel extract of Punica granatum was found maximum in phenol, alkaloid, and terpenoid content.

The HPLC analysis of anonaine compound from A. reticulata fruit peel extract along with the standard anonaine has been represented in Fig. 5. Anonaine compound was eluted through HPLC analysis and based on standard retention time (Rt) $12.32 \mathrm{~min}$. The A. reticulata fruit peel extract (Ooty accession) used for HPLC analysis recorded Rt of $12.39 \mathrm{~min}$ and standard anonaine compound recorded Rt of $12.32 \mathrm{~min}$, thus confirming the presence of anonaine compound in fruit peel extract of A. reticulata.

\section{CONCLUSION}

The present study revealed that aqueous peel extract of $A$. reticulata was rich in phytochemical constituents and high levels of total phenolic, flavonoid and alkaloid compounds. The peel extract of A. reticulata also possessed strong antioxidant potential and was thus capable of inhibiting, quenching free radicals to terminate the radical chain reaction. The HPLC analysis revealed the identification of active compound, namely anonaine, present in the fruit peel extract of A. reticulata. The results indicate that the plant material may become an important source of natural drug compounds with health protective potential and natural antioxidants of significant impact on the status of human health and disease prevention.

\section{ACKNOWLEDGEMENTS}

The author, Dr. Sumathi Ethiraj, Assistant professor and Principal Investigator acknowledges the Department of Science and Technology, Science and Engineering Research Board (DST-SERB), Government of India, for the financial support provided under the Young Scientist Scheme (File no. YSS/2015/001610).

\section{AUTHORS' CONTRIBUTIONS}

The first author, Dr. Sumathi Ethiraj, is the Principal Investigator (PI) of the present research work. The second author Vandana Sridar, JRF, assisted the PI in the experimental work. The first author performed collection of sample, extraction, analysis, manuscript preparation, its revision and is the corresponding author.

\section{CONFLICTS OF INTEREST}

The authors declare that there is no conflict of interest.

\section{REFERENCES}

1. Sukanya SL, Sudish J, Hairprasad P, Niransjana SR, Prakash HS, Fathima SK. Antimicrobial activity of leaf extracts of Indian medicinal plants against clinical and phytopathogenic bacteria. Afr J Biotech 2009;8:6677-82.

2. Lobo V, Patil A, Phatak A, Chandra N. Free radicals, antioxidants and functional foods: Impact on human health. Pharmacogn Rev 2010;4:118-26.

3. George M, Joseph L, Ramaswamy. Anti-allergic, anti-pruritic and anti-inflammatory activities of Centella asiatica extracts. Afr J Tradit Complement Altern Med 2009;6:554-9.

4. Bhandary SK, Kumari N, Bhat VS, Sharmila K, Bekal MP. Preliminary phytochemical screening of various extracts of Punica granatum peel, whole fruit and seeds. Nitte Univ J Health Sci 2012;2:34-8.

5. Maria KM, John M, Ayyanar T, Arumugam G, Enkhtaivan K, et al. Phytochemical screening and antioxidant activity of different solvent extracts from Strychnos minor Dennst leaves. Asian Pac J Trop Dis 2015;5:204-9.

6. Thielecke F, Boschmann M. The potential role of green tea catechins in the prevention of the metabolic syndrome-a review. Phytochemistry 2009;70:11-24.

7. Parveen R, Nazshamsi T, Kumar H, Fatima S. Phytochemical analysis and in vitro biological characterization of aqueous and methanolic extract of Bacopa monnieri. Int J Pharm Pharm Sci 2016;8:90-6.

8. Aboul-Enein AM, Abu-Elalla F, Shalaby EA, El-Shemy HA. Traditional medicinal plants research in Egypt: Studies of antioxidant and anticancer activities. J Med Plants Res 2012;6:689-703.

9. Khan RA, Khan MR, Sahreen S, Ahmed M. Evaluation of phenolic contents and antioxidant activity of various solvent extracts of Sonchus $\operatorname{asper}($ L.) Hill. Chem Cent J 2012;6:1-7.

10. Neelam V, Nitu T. HPLC Analysis of methanolic extract of herbs for Quercetin content. J Pharmaco Phytochem 2013;2:159-62.

11. Lakhanpal P, Rai KD. Quercetin: A versatile flavonoid. Int J Med Update 2007;2:22-37.

12. Gulcin I. Antioxidant activity of food constituents: An overview. Arch Toxicol 2012;86:345-91.

13. Peschel W, Sanchez-Rabaneda F, Dieckmann W, Plescher A, Gartzia I, Jimenez D, et al. An industrial approach in the search of natural antioxidants from vegetable and fruits wastes. Food Chem 2006;97:137-50.

14. Hanachi P, Golkaho SH. Using HPLC to determination the composition and antioxidant activity of Berberis vulgaris. Eur J 2009;29:47-54.

15. Sarma BK, Singh UP, Sing KP. Variability in Indian isolates of Sclerotium rolfsi. Mycologia 2002;94:1051-8.

16. Saad JM, Huri Y, Rupprecht JK, Anderson JE, Kozlowski JF, Zhao G, et al. Reticulatacin: A new bioactive acetogenin from Annona reticulate 
(Annonaceae) Tetrahedron 1991;47:2751-6

17. Jamkhande S, Wattamwar A. Annona reticulate L. plant profile, phytochemistry and pharmacological properties. J Trad Complement Med 2016;2016:248-57.

18. Wong PY, Kitts DD. Studies on the dual antioxidant and antibacterial properties of parsley (Petroselinum crispum) and cilantro (Coriandrum sativum) extracts. Food Chem 2006;97:505-15.

19. Pawar S, Kamble V. Phytochemical screening, elemental and functional group analysis of Vitex negundo L leaves. Int J Pharm Pharm Sci 2017;9:226-30.

20. George $\mathrm{H}$, Teng $\mathrm{CM}$, Wu CL, Ko FN. Marchantin has a natural antioxidant and free radical scavenger. Arch Biochem Biophys 1996;334:18-26.

21. Anbukkarasi M, Dhamotharan R, Janarthanam B. Studies on phytochemical screening, tannins content and antibacterial activity from leaf and callus extracts of Memecylon umbellatum. Asian J Pharm Clin Res 2017;10:265-9.

22. Slinkard K, Singleton VL. Total phenol analysis: Automation and comparison with manual methods. Am J Enol Vitic 1977;28:49-55.

23. Mervat MM, Far El, Hanan A, Taie A. Antioxidant activities, total anthocyanins, phenolics and flavonoids contents of some sweetpotato genotypes under stress of different concentrations of sucrose and sorbitol. Aust J Basic Appl Sci 2009;3:3609-16.

24. Edeoga HO, Okwu DE, Mbaebie BO. Phytochemical constiuents of some Nigerian medicinal plants. Afr J Biotechnol 2005;4:685-8.

25. Okwu DE, Josiah C. Evaluation of the chemical composition of two Nigerian medicinal plants. Afr J Biotechnol 2006;5:357-61.

26. Janarthanam B, Sumathi E. Optimization of biomass culture yield and L-dopa compound in the callus culture from cotyledonary leaves of Mucuna pruriens. Asian J Pharm Clin Res 2015;8:282-6.

27. Shimizu T, Muroi T, Ichi T, Nakamura M, Yoshihira K. Analysis of red cabbage colors in commercial foods using high performance liquid chromatography with photodiode array detection-mass spectrophotometry. J Food Hyg Soc Japan 1997;38:34-8.

28. Jamuna S, Subramaniam P, Krishnamoorthy K. Phytochemical analysis and evaluation of leaf and root parts of the medicinal herb Hypochaeris radicata $\mathrm{L}$. for in vitro antioxidant activities. Asian Pac J Trop Biomed 2014;4:S359-67.

29. Bhatt V, Bhati GS, Gupta S. Evaluation of free radical scavenging behaviour and antioxidant activity in various citrus fruits. Euro J Adv Eng Tech 2016;3:40-4

30. Tepe B, Sokmen M, Akpulat HA, Sokmen A. Screening of the antioxidant potentials of six Salvia species from Turkey. Food Chem 2006;95:200-4.

31. Mammadov R, Ili P, Vaizogullar HE. Antioxidant activity and total phenolic content of Gagea fibrosa and Romulea ramiflora. Iran J Chem Chem Eng 2011:30:57-62.

32. Suresh PK, Sucheta S, Sudarshana VD, Selvamani P, Latha S. Antioxidant activity in some selected Indian medicinal plants. Afr J Biotechnol 2008;7:1826-8.

33. Rice-Evans CA, Sampson J, Bramley PM, Holloway DE. Why do we expect carotenoids to be antioxidants in vivo? Free Radic Res 1997;26:381-98.

34. Rathanavel C, Arasu PT. Antioxidant activity, phenol and flavonoid contents of some selected Indian medicinal plants. Int J Curr Microbiol App Sci 2014;3:830-8

35. Xu XL, Zou J, Liu Y, Peng H, Wu Q. Medicinal function, separation and purification of alkaloids: A review. Chem Eng Sci 2009;48:3835-43.

36. Omulokoli E, Khan B, Chabra SC. Anti-plasmodial activity of four Kenyan medicinal plants. J Ethnolopharmacol 1997;56:133-7.

37. Monica V, Raquel H, Pinyi L, Bassaganya J. Preventive and prophylactic mechanisms of action of pomegranate. Bioact Constit 2013;18:1-18

38. Ibrahim OM, Shwaysh MM. Evaluation of Punica granatum peels extracts and its phenolic, alkaloid and terpenoid constituents against chemically induced diarrhoea in rats. Advan Anim Vet Sci 2016;4:161-8. 